\title{
Transdisciplinary Research in Higher Education: Towards a Paradigm for Sustainable Development
}

\author{
${ }^{1}$ Norman Rudhumbu, ${ }^{2}$ Leocadia Zhou, ${ }^{3}$ Kenneth Nhundu \\ ${ }^{1}$ Botho University, P.O. Box 501564, Gaborone, Botswana \\ ${ }^{2,3}$ University of Fort Hare, Alice Campus, P. Bag X 1314, Eastern Cape, South Africa
}

\begin{abstract}
This review provides an understanding of and justification for the transdisciplinary research(TDR) as an action-oriented research approach in higher education that promotes sustainabledevelopment in society. Current studies on TDR show that today more than ever before, there is a shifting landscape of knowledge generation in contemporary societies owing to the nature and number of challenges society is seized with which among others include political strife, hunger, unemployment, diseases, and urban migration. Little attests to the fact that societal problems have become too complex for one point of view as provided for by disciplinary research. The need therefore to make research relevant and contextual in addressing these complex reallifechallenges facing society today cannot be overemphasized when looked at in the context of sustainable development. This review argues that contemporary sustainable development challenges, complex as they are, demand cooperation between specialists and social actors with diverse backgrounds of knowledge and experiencesto be able to effectively track the challenges and come up with practical and contextualized solutions. This review employs document analysis to generate a deeper understanding as well as to proffer a cogent argument for the need for transdisciplinary research in solving contemporary socio-ecological challengesthroughco-production of knowledge in concrete real-life contexts.
\end{abstract}

\section{Introduction}

Poverty, degradation of natural resources, food insecurity, diseases, urban migration, technological changes, internal conflicts, unemployment and others, are some of the complex socio-ecological challenges facing humanity today that require a convergence of intelligences across disciplines for practical and effective solutions to be generated (Zerfu et al, 2011). This calls for a paradigm shift in research hence the choice forTDR which is a research paradigm that goesgoing beyond disciplinary boundaries and seeks to integrate different disciplinary perspectives. TDR is thus referred to asan innovative approachto fundamental scientific understanding of specific problems facing society today and in future (Raymond et al, 2010; Harris \& Lyon, 2013). Besharov and Smith (2014)and also Botha et al (2014) attest that TDR is a milestone in research and knowledge generation that has potential to transform traditional research through the introduction of an allstakeholder and participative form of research.Studies show that TDR, as a communities of practice, is composed of distinctively heterogeneous, cross-sectorial groups (right from research professors to social actors in communities) with a shared interest and basic commitment to solving complex socio-ecological problems (Crona \&Parker, 2011). This commitment is shown by the way individuals engage one another to co-produce knowledge for practical application to current challenges, and more importantly, how these people on an ongoing basis, get involved in an iterative process of issue framing, knowledge production, and knowledge application (Roux \& Nel, 2013; Parker \& Crona, 2012; Crona \& Parker, 2011).

This review therefore is guided by the following research question: Why, in contemporary society, should it be necessary to change the way of knowledge production in favour of transdisciplinary research?

\section{Conceptual framework Defining TDR}

Studies show that there is no standard template of what transdisciplinary research should look like or what steps it must follow but what is known though is that it is a problem- or issue-centered research paradigm also known as a part of responsive methodologies (Maynard, 2013). The concern of TDR is sustainability through multi-stakeholder co-production of knowledge where all participants to the research are viewed as collaborating actors rather than viewed separately and differently as academics, researchers, farmers, etc., in order to build a sense of oneness (Hegger et al, 2012; Brandt et al, 2013). The question then that is asked is: "What then is TDR?" Transdisciplinary Research on Energetics and Cancer (TREC) (2010) define TDR as a team science where researchers transcend their own disciplines to inform one another's work, capture complexity and co-create new intellectual spaces. From the above definition, TDR therefore connotes a research strategy that crosses multi-disciplinary boundaries to make research more holistic by focusing on problems that cut across discipline boundaries (Jahn et al, 2012). Similarly Pennington et al (2013) define TDR as a type of 
contemporary research that integrates a variety of academic and non-academic perspectives to come up with issue-centered knowledge. Lang et al (2012) as well as Vilsmaier and Lang (2014) also define TDR as a new production of knowledge or as contextualized research that seeks to create a stronger link between knowledge production and societal transformation. This definition means that research should not be for its own sake or for knowledge's sake but should seek to make society better. TDR is also defined as a type contextualized research that, with strong links to societal spheres or spaces, is meant to generate knowledge and practices that serve sustainable development in society (Pohl\& Hadon, 2007; Krohn, 2010; Jahn et al, 2012). Scholz (2011) also defines TDR as a paradigm shift that recognises research as a science with society rather than a science for society through the creation of spaces for joint knowledge production and societal transformation. TDR therefore is meant to resolve research contractions caused by disciplinary boundaries.

From all the above definitions, it can therefore be argued that TDR research bridges the traditional boundaries between disciplines and also between academia and practice and hence challenges conventional approaches to research within academia where knowledge is organized within rather than across disciplines.By harnessing contributions from each of research experts, laymen and the public, TDR challenges fundamental principles of scientific research (Duspohl et al, 2012; Harris \& Lyon, 2014).

\section{The Disciplinary Research - TDR continuum}

The continuum between disciplinary research and TDR can be defined not only in terms of how disciplines choose to do research but also in terms of the extent to which problem owners (communities) participate in the research process. The continuum is composed of disciplinary, multidisciplinary, interdisciplinary and transdisciplinary research approaches.

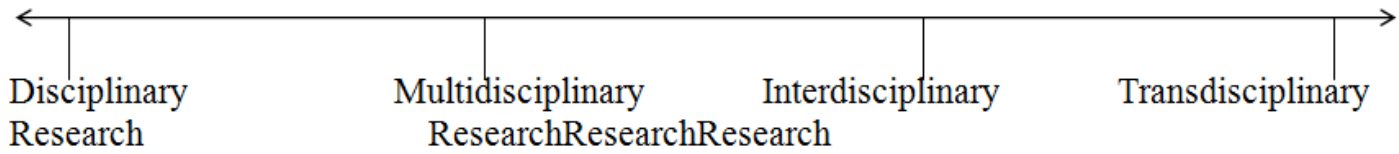

Figure 1: Disciplinary - Transdisciplinary research continuum (Research work)

\section{Disciplinary research}

Disciplinary or monodisciplinary research is a research that draws on knowledge from a single discipline, that is, it is carried out within the boundary of a single academic discipline as in finance, economics, biology etc. (Habermann et al, 2013).It is a research that is executed by individuals or a group of experts from a single discipline that seeks to answer a specific research question (Tress et al, 2006).It can be noted from Figure 2 that researchers from different academic disciplines work alone and that crucially, problem owners who are the community members are not involved at all in the research of the problem affecting them.

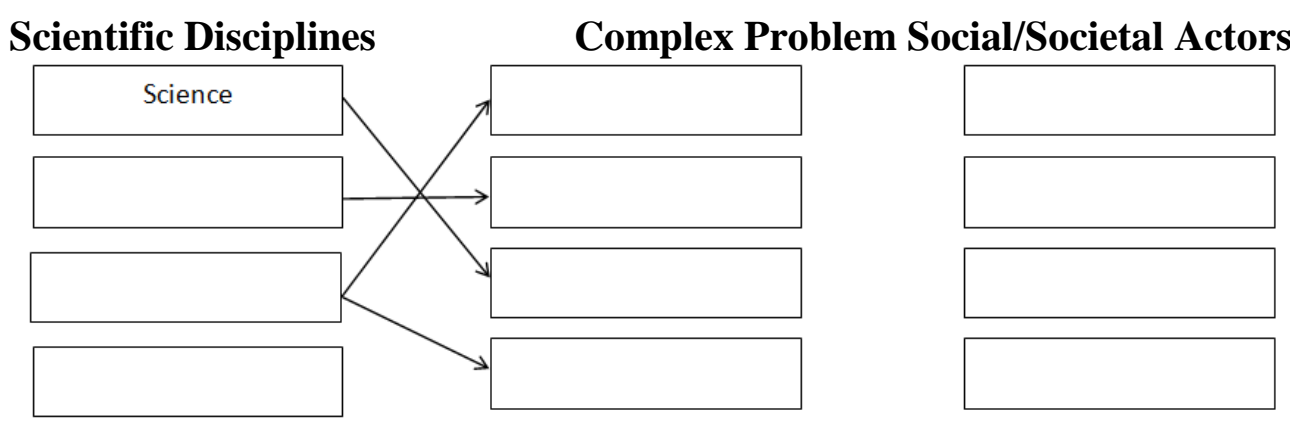

Figure 2: Disciplinary Research (Harbermann et al, 2013)

Such a research according to Miller et al (2008) not only produce out-of context solutions but also potentially limits variety of scientific and local language or terminology that can contribute and even deepen our understanding of issues at hand and the generation of new knowledge required to solve a problem.

\section{Multidisciplinary research}

Multidisciplinary research draws on knowledge from different disciplines but stays within their boundaries (Toomey et al, 2015). The above means that multidisciplinary research involves different academics from different academic disciplines working together on one research problem but with multiple disciplinary goals (Zerfu et al, 2011). 


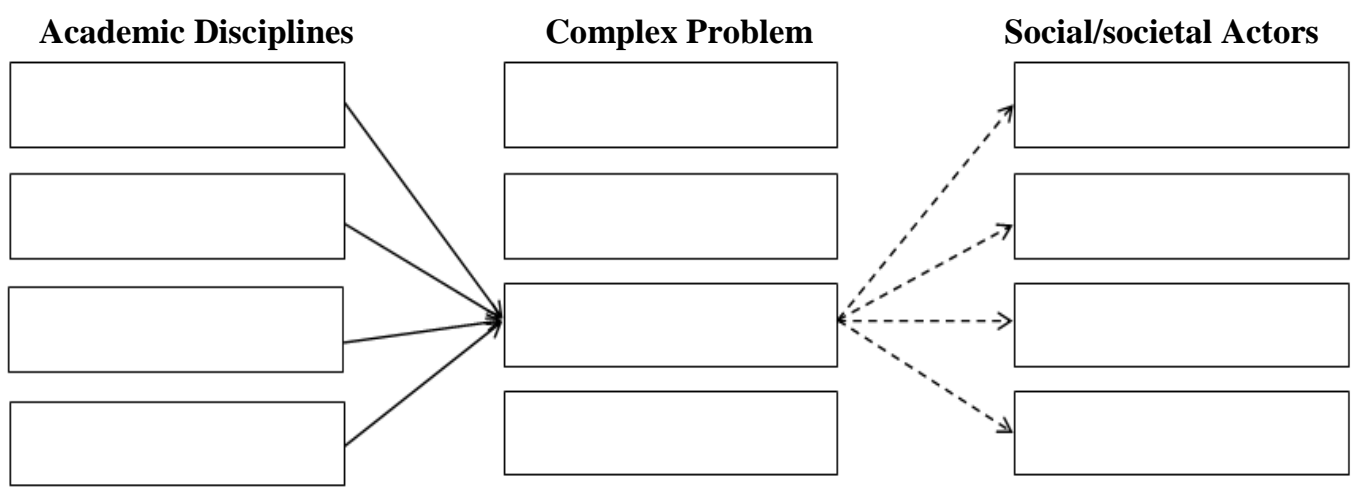

Figure 3: Multidisciplinary Research (Toomey et al, 2015)

In this approach, participants exchange ideas but do not work together to co-generate new knowledge, that is, after agreeing that there is a problem to be researched on, there is parallel research by disciplines with the aim of comparing results at the end (Miller et al, 2008). The above research approach shows therefore that researchers remain in theirown epistemological spaces or perspectives and seek to create and validate new knowledge within those spaces (Miller et al, 2008; Geels, 2014). The approach as shown in Figure 3 does not involve implementers (social actors) but simply prescribes what is believed to be solutions and such solutions according to Harris and Lyon (2013) may suffer from the buy-in problem on the part of social actors.

\section{Interdisciplinary research}

As shown in Figure 4, interdisciplinary research links disciplines into a coordinated whole (Choi, 2006; Pohl \& Hardon, 2007). It is a type of research implemented by teams or individuals that integrate data, techniques, perspectives and/or theories from two or more disciplines or bodies of knowledge in order to advance fundamental understanding or to solve problems whose solutions are beyond the scope of a single discipline (Habermann et al, 2013; Zerfu et al, 2011).

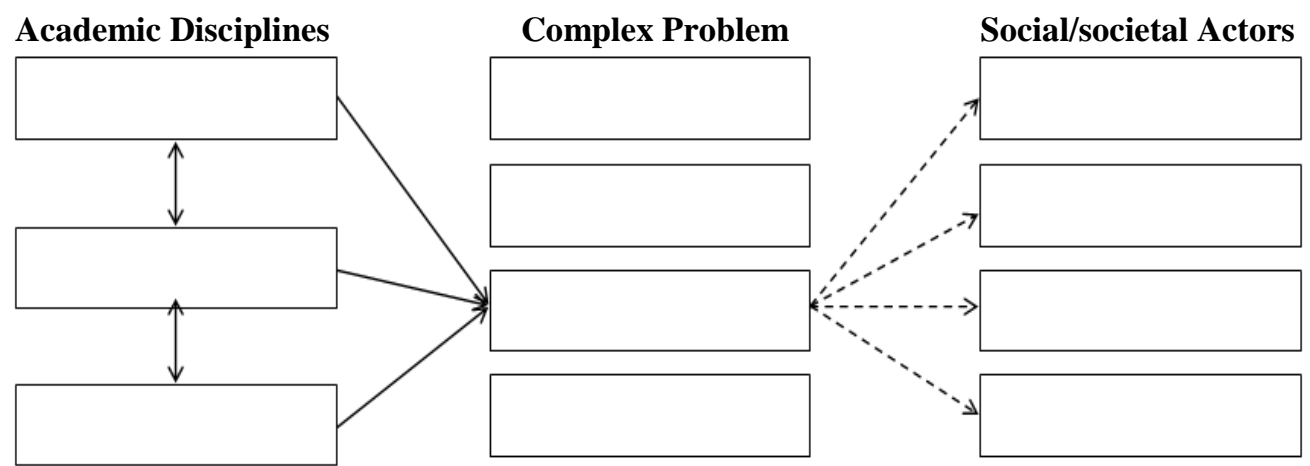

Figure 4: Interdisciplinary research (Pohl \& Hardon, 2007)

Integration in the interdisciplinary research is mostly done through unified problem formulation, sharing of methodologies, and in some cases through the co-creation of research questions (Pohl \& Hardon, 2007; Duspohl et al, 2012). Participation of social actors in the research process is through receiving prescribed results and the issue of buy-in of these research results could be the archiles heel to the effective implementation of research results.

\section{Transdisciplinary research $(T D R)$}

The premise of TDR is that socio-ecological challenges facing humanity need to be tracked and solved by all stakeholders hence it is a research that goes beyond mere production of knowledge to the practical use of the knowledge outside academia. In essence, it takes into consideration the societal impact of knowledge as what should be the main aim of research (Harris \& Lyon, 2014; Toomey et al, 2015). This action- or practiceoriented nature of TDR is as shown in Figure 5.Because TDR considers in equal measure the perspectives of all stakeholders, that is, the academics and social actors, it is sometimes referred to as more than just a research approach but rather as a dialogue across boundaries (Hardon, 2008). Figure 5 is a demonstration of the practical implementation of TDR. As can be observed from Figure 5, TDR integrates academic researchers from different disciplines and non-academic participants for a common goal of co-creating new knowledge. 


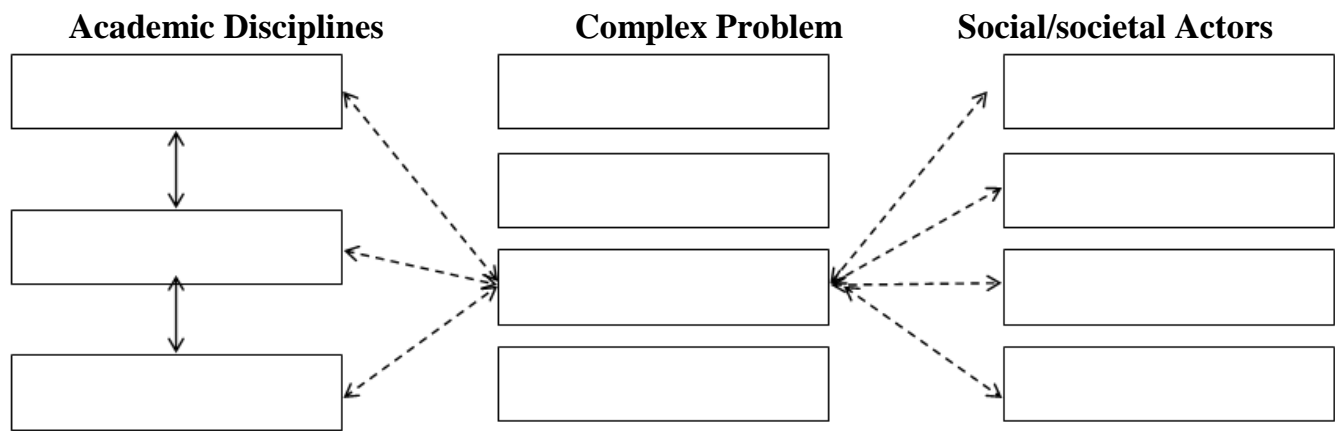

Figure 5: Transdisciplinary research (Harris \& Lyon, 2014)

Algebraically TDR is defined as interdisciplinary research + interested groups (stakeholder, problem owners) who are involved in all phases of the research process (Habermann et al, 2013). It is a research that links abstract knowledge (from academics) and case specific knowledge (from social actors) in order to develop new knowledge and practices that promote common good in society (Pohl \& Hardon, 2008; Maynard, 2013). According to Pohl and Hardon (2008), TDR is used under the following circumstances: i) when knowledge about the problem is uncertain, ii) when the exact nature of the problem is disputed, and iii) when there is a great deal at stake for those concerned by the problem and involved in dealing with it. By allowing all relevant stakeholders to the central problem to take part, TDR allows a situation where all participants provide a diversity of perspectives, complementing each other, the result of which is a more complete description of knowledge than any single researcher can do alone (Miller et al, 2008; Pohl et al, 2010; Phillipson et al, 2012).

A summary of the four different research approaches is as shown in Table 1 which shows that disciplinary (monodisciplinary) research as well as multidisciplinary research are employed when attempting to solve simple problems. On the other hand, interdisciplinary is used for solving complicated but not complex problems where researchers exchange information (research methods and knowledge) and integrates knowledge across disciplines but with little involvement of social actors. TDR according to Table 1 is used when dealing with complex problems that require concerted efforts of participants across disciplines as well as social actors. Its main focus is to ensure co-generated knowledge is effectively put into practice y involving social actors in the research of their problem right from the start so that there is ownership of both the search for the solution (research strategies) and solution by especially those who will be tasked to implement, that is, the social actors.

Table 1: Summary of the Four Research Approaches(Miller et al, 2008)

\begin{tabular}{|c|c|c|c|}
\hline Single Disciplinary $\longleftarrow$ & Multi-disciplinary & Interdisciplinary & Transdisciplinary \\
\hline $\begin{array}{l}\text { Highly specialized in } \\
\text { one discipline }\end{array}$ & $\begin{array}{l}\text { People from different } \\
\text { disciplines } \\
\text { together, each drawing on } \\
\text { their } \\
\text { knowledge. }\end{array}$ & $\begin{array}{l}\text { Integrating knowledge } \\
\text { and methods from } \\
\text { different disciplines, } \\
\text { using a real synthesis of } \\
\text { approaches. }\end{array}$ & $\begin{array}{ll}\text { Creating a unity of } \\
\text { intellectual } \\
\text { beyond the } \\
\text { perspectives. }\end{array}$ \\
\hline $\begin{array}{l}\text { No cooperation with } \\
\text { other disciplines }\end{array}$ & $\begin{array}{l}\text { Not focused on problem } \\
\text { solving but requires expert } \\
\text { opinions }\end{array}$ & $\begin{array}{l}\text { Focused on problem } \\
\text { framing and solving from } \\
\text { disciplinary perspectives }\end{array}$ & $\begin{array}{l}\text { Solving problems by going } \\
\text { beyond disciplinary } \\
\text { perspective to involving } \\
\text { practitioners, beneficiaries } \\
\text { and non-academia }\end{array}$ \\
\hline \multirow[t]{3}{*}{ 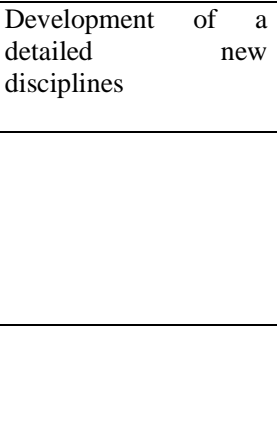 } & $\begin{array}{l}\text { Members cooperate in their } \\
\text { contributions but do not } \\
\text { integrate their perspectives, }\end{array}$ & $\begin{array}{l}\text { Perspectives are } \\
\text { integrated with stronger } \\
\text { levels of cooperation }\end{array}$ & $\begin{array}{l}\text { New knowledge is } \\
\text { generated through the use of } \\
\text { multi and interdisciplinary } \\
\text { concepts }\end{array}$ \\
\hline & $\begin{array}{l}\text { Disciplinary } \\
\text { development }\end{array}$ & $\begin{array}{l}\text { There is a common } \\
\text { understanding } \\
\text { methodological } \\
\text { approaches } \\
\text { epistemological and } \\
\text { ontological perspectives }\end{array}$ & $\begin{array}{l}\text { Considered as the highest } \\
\text { form of integration of all } \\
\text { actors in a participatory } \\
\text { approach form to solving } \\
\text { real life problems }\end{array}$ \\
\hline & & & $\begin{array}{l}\text { It synthesis or integrate new } \\
\text { disciplines and theory } \\
\text { among science and society }\end{array}$ \\
\hline
\end{tabular}

\section{Characteristics of TDR}

There are a number of features that help to characterise TDR as a unique yet pragmatic (it is actionoriented) approach to solving real-life problems in society. The first characteristic according to TREC (2010) is that TDR accepts diversity of perceptions and perspectives for the common good of all stakeholders. This acceptance is demonstrated when participating individuals from across disciplines and contexts engage in open 
discussion and dialogue, giving equal weight to each perspective and relating to each other. The above view is mirrored in the assertion by Miller et al (2008) who allude to the fact that TDR leads to the use of a common research framework or plan based on a multiplicity of perspectives from diverse participants. The above is why TDR according to Harris and Lyon (2014) is viewed as signifying a unit of knowledge beyond disciplines. The second characteristic relates to the fact that TDR allows the inclusion of all stakeholders, that is, those researching and those affected by the problem for which research is to be done, in jointly coming up with research objectives (TREC, 2010). This characteristic implies that TDR is uniquely capable of engaging with different ways of knowing the world, generating new knowledge, and helping stakeholders understand and incorporate the results or lessons learned from the research (Klein, 2010). By allowing participation of problem owners (the social actors), TDR enables these social actors to share their values, beliefs and norms that have a significant influence on nature of new knowledge to be produced for solving complex societal problems. The third characteristic of TDR is that it accepts that the spaces between disciplines and beyond disciplines is rich in knowledge (Pennington et al, 2013). This means by accepting that researchers can complement each other's research efforts, they are able to come up with richer and more informed solutions that when there is compartmentalization of efforts and knowledge. The fourth characteristic is that TDR is both dynamic and reflexive in that it allows for an assured flow between knowledge production and its practical application (Smith, 2007). This characteristic implies that TDR is not just research for its sake but is research for pragmatic reasons.

Based on the above characteristics therefore, the main tenets of TDR are that team members i) should have a deep understanding/knowledge in their areas of expertise, ii) should have a shared commitment to finding a solution to an identified societal problem, iii) should have a shared ethical and value systems for collaborative engagement in the team, iv) should be able to easily network among themselves, and v) should be people who have institutional access to required funding, materials, experimental and technological resources (Roux \&Nel, 2013; Pennington et al, 2013). It is important according to Pennington et al (2013) that while the five tenets of TDR do not necessarily lead to a creative solution to a societal challenge, they more importantly ensure the presence of both a conducive research environment as well as a conducive knowledge-integration process across disciplines.

\section{Strengths and weaknesses of TDR}

TDR has a number of strengths and weaknesses with strengths outweighing weaknesses. Among some of the strengths of TDR are the following(Cronin, 2008; Jahn et al, 2012; Maynard, 2013): i) it allows for the creation of new knowledge by crossing disciplinary boundaries, i.e., it accepts that spaces between disciplines are rich in knowledge, ii) it supports the analysis of complex problems from different perspectives resulting in a detailed understanding of issues at hand, iii) it enables the participants to deal with complexity, uncertainty, change and imperfection effectively and efficiently by sharing knowledge and integrating intelligences during research, iv) it encourages system (holistic) thinking and guides the participants to look at the whole issue (through a bigger picture perspective) and its relationship to its parts, v) it involves the researchers and the public (social actors) in the whole research process thus enabling the integration of multiple knowledges and overcoming epistemological barriers between academia and non-academia, vi) it enlarges the view and perspective of participants to incorporate issues outside disciplinary boundaries (contextual issues), vii) it enables participants to jointly learn about (and understand) the complex problems and to facilitate knowledge exchange, and viii) it targets social issues or needs and expectations hence bridges the gap between research and practices.

Among some of the weaknesses or challenges in the use of TDR are theoretical, methodological and practical challenges (Cronin, 2008; Botha et al, 2014; Mauz et al, 2012; Harris \& Lyon, 2014). Among practical challenges include that TDR is time consuming. This is so because it requires extra timeto build consensus and for diverse participants to learn new approaches from other's knowledge systems. The second practical challenge is the potential incommensurability of specialised languages between participants from different fields of expertise among academics and also from the knowledge systems of social actors.Such a challenge may lead to communication challenges between academia and non-academia with regards to technical jargon relevant to research. To deal with the issue of communication, TREC (2010) argues that TDR researchers should not only have in-depth knowledge and know-how of their disciplines but should also have skills in moderation, mediation, association and transfer of knowledge.If the above issue is not adequately taken into consideration, the third practical challenge that would arise in TDR amongthe diverse members would be conflicts in issue framing and in validating different knowledges (Jahn et al, 2012; Harris \& Lyon, 2014; Scholz, 2011). In order to manage these tensions in TDR, Harris and Lyon (2014) suggest the following strategies based on the premise that TDR does not only require the management of diversity but also of tangled agendas : i) recognising diversity of values, methods, and reward systems among participants as to some rewards are tangible while to others they are intangible. Harris and Lyon (2014) argue that the success of TDR is contingent on the values, 
expectations, culture, and reward structures of all participants to the research process, ii) selection of research teams needs to balance optimizing team size and diversity so that teams are large enough to be diverse but small enough to build working relationships. Harris and Lyon (2014) further expand on the above point by saying that having such teams encourages knowledge creation without overwhelming cognitive distance between participants, and iii) building trust in collaboration while being sensitive to how unequal power relations can shape the success of the TDR process.

In their discussion of lack of coherent framing as a theoretical challenge in TDR Lang, et al, 2012) noted that a lack of a shared framing of problems might occur when researchers from a multiplicity of disciplines and research traditions take different perspectives on the same problem. It is further argued in another study by Brandt et al (2013) that a lack of a shared framing of a research problem as a result of a lack of adequate interaction between researchers and context players (social actors or practitioners) may pose added challenges to the co-production of robust knowledge and to solving a sustainability problem. Winder (2003) in earlier studies also argued that a lack of shared framing of a research problem can also hamper scientific communication and knowledge exchange between disciplines that do not share methodological or conceptual definitions. To address this interaction challenge, authorities in TDR argue that there has to be acceptance of mutual learning between researchers and practitioners (Scholz, 2011; Stahl et al, 2011). Kruetli et al (2010) in their discussion of practitioner engagement, argue that for TDR to be successful, interaction between researchers and practitioners should, on a continuum (Figure 6), move from information, consultation, collaboration to empowerment.

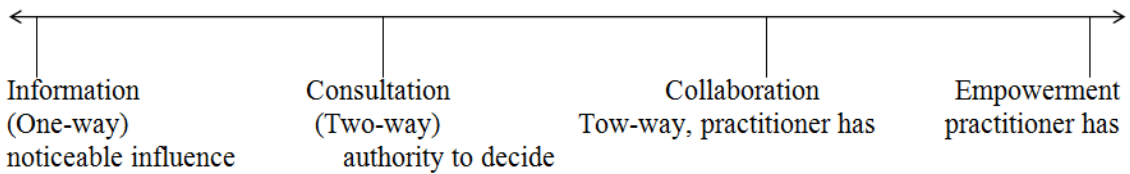

Figure 6: Communication continuum in TDR (Kruetli et al, 2010)

With regards to the methodological challenge, it is asserted in a number of studies that besides developing coherent terminologies and research frameworks, TDR requires both the integration of different disciplinary methods and the development of new research methods to enable efficient and effective learning processes at the science (academic)-society (practitioners or social actors) interface (Bergmann, 2010; Bergmann \& Schramm, 2008).By way of summary, in the light of the three major challenges of TDR namely the practical, theoretical and methodological challenges as mentioned above, Harris and Lyon (2014) opine that to therefore effectively negotiate the TDR process, facilitator and stakeholder workshops to build good communication, manage diverse expectations, build trust, and also to ensure equality of all participants should be done at an early stage of the research process.

\section{Conclusion}

The review showed that TDR is the only research that is able to solve complex problems that affect society as it involves problem owners from society in the research process. Based on the complexity of societal problems/challenges, TDR can be effective, integrative and solution-oriented approach capable of transcending disciplinary boundaries and that allows social actors (problem owners) to participate as equal partners. TDR is an approach that ensures that whatever new knowledge is co-produced is owned by all involved and hence ensures effective implementation of solutions proposed to solve societal problems. While a number of challenges to the success of TDR as a research paradigm were identified, it was also observed in thisstudy that there are more strengths of TDR than weaknesses. Critically, the study showed that by ensuring that social actors participate in all phases of the research process, TDR empowers the social players (community members) who are concerned or affected by the problem so that they are able to effectively and willingly implement the solutions to their problems generated by research. This study also showed that other research approaches which work in isolation of social players potentially produce and prescribe non-workable solutions that have little or no relevance to the needs of social actors at all hence theresearch findings end up just gathering dust in cupboards.

\section{References}

[1]. Bergmann, M. \&Schramm, E.(2008).TransdisziplinäreForschung. IntegrativeForschungsprozesseverstehen und bewerten. Frankfurt/New York: Campus Verlag

[2]. Bergmann, M., Jahn, T., Knobloch, T., Krohn, W., Pohl, C., Schramm, E. (2010).Methoden transdisziplina "rerForschung: Ein U "berblickmitAnwendungsbeispielen. Frankfurt/Main: Campus Verlag.

[3]. Besharov, M, Smith, W. (2014). Multiple Logics in Organizations: Explaining Their Varied Nature and Implications.Academy of Management Review, 39(3):364-381 Botha, N, Klerkx, L, Small, B, Turner, JA. (2014). Lessons on transdisciplinary research in a co- innovation programme in the New Zealand agricultural sector. Outlook on Agriculture, 43:219-223

[4]. Brandt, P., Ernst, A., Gralla, F., Luederitz, C., Lang, D. J., Newig, J., Reinert, F., Abson, D. J.,Von Wehrden, H. (2013). A review of transdisciplinary research in sustainability science.Ecological Economics, 92: 1-15

[5]. Choi BCK, Pak A.W.P. (2006). Multidisciplinarity, interdisciplinarity and transdisciplinarity in health research, services, education and policy: 1. Definitions, objectives, and evidence of effectiveness. Clinical \& Investigative Medicine, 29:351-64. 
[6]. Crona, B. I.\& Parker, J. N. (2011). Network determinants of knowledge utilization: preliminary lessons from a boundary organization. Science Communication, 33(4):448-471.

[7]. Cronin, K. (2008). Transdiciplinary research (TDR) and Sustainability. Overview report prepared for the Ministry of Research, Science and Technology (MoRST).Retrived from www.learningforsustainability .net/.../Transdisciplinary_ Research_and_ Sustaina.pdf. [Accessed: $7^{\text {th }}$ august 2016].

[8]. Düspohl M, Frank S, Döll P (2012) A review of Bayesian networks as a participatory modeling approach in support of sustainable environmental management. Journal of Sustainable Development, 5(12):1-18.

[9]. Geels, F. W. (2014). Reconceptualising the co-evolution of firms-in-industries and their environments: Developing an interdisciplinary Triple Embeddedness Framework. Research Policy, 43.2: 261-277.

[10]. Habermann, B., Misganaw, B., Peloschek, F., Dessalegn, Y. \& Selassie.Y.G. (2013).Inter-and Transdisciplinary Research Methods in Rural Transformation. Case studies in Northern Ethiopia. BOKU Vienna: Centre for Development Research - CDR/ University of NaturalResources and Life Sciences.

[11]. Harris, F.\& Lyon, F. (2014).Transdisciplinary environmental research: a review of approaches to knowledge co-production. Retrieved from www.thenexusnetwork.org/join.[Accessed: $17^{\text {th }}$ August 2016].

[12]. Harris, F, Lyon, F. (2013).Transdisciplinary environmental research: Building trust across professional cultures.Environmental Science and Policy, 31:109-119.

[13]. Hegger, D, Lamers, M, Van Zeijl-Rozema, A, Dieperink, C. 2012.Conceptualising joint knowledge production in regional climate change adaptation projects: Success conditions

[14]. and levers for action.Environmental Science and Policy, 18:52-65.

[15]. Jahn, T., Bergmann, M.\&Keil.F. (2012).Transdisciplinarity: Between mainstreaming and marginalization. Ecological Economics, 79:1-10

[16]. Klein, J. T. (2010). A taxonomy of interdisciplinarity. In R. Frodeman, J.T. Klein, \& C. Mitcham (Eds.) Oxford handbook of interdisciplinarity. Oxford: Oxford University Press.

[17]. Krohn, W. (2010).Interdisciplinary Cases and Disciplinary Knowledge. In: R. Frodeman, J.

[18]. Thompson Klein and C. Mitcham (eds.): The Oxford Handbook ofInterdisciplinarity.Oxford: Oxford University Press, 31-38;

[19]. Kruetli, P. Stauffacher, M. Flüeler, T. \&Scholz, R.W. (2010). Functional-dynamicpublic

[20]. participation in technological decision-making: Site selection processes of nuclear waste repositories. Journal of Risk Research, 13: $861-875$.

[21]. Lang, D. J., Wiek, A., Bergmann, M.,Stauffacher, M., Martens, P., Moll, P., Swilling, M. \&Thomas, C. J. (2012). Transdisciplinary research in sustainability science: practice, principles, and challenges. Sustainability Science, 7(1):25-43.

[22]. Mauz, I., Peltola, T., Granjou, C., van Bommel, S., Bujis, A. (2012). How scientific visions matter: insights from three long-term scoio-ecologicalresearch (LTSER)platforms under construction in Europe. Environmental Science and Policy, 19-20, 90-99.

[23]. Maynard, CM. (2013). How public participation in river management improvements is affected by scale. Area, 45(2):230-238.

[24]. Miller T.R., Baird, T.D., Littlefield, C.M., Gary Kofinas, G., F. Stuart Chapin, F.S. \& Charles L.

[25]. Redman, C.L. (2008). Epistemological Pluralism: Reorganizing Interdisciplinary Research. Ecology and Society, $13(2)$ : 46.

[26]. Mobjörk, M. (2010). Consulting versus participatory transdisciplinarity: a refined classification

[27]. of transdisciplinary research. Futures, 42:866-873

[28]. Parker, J. and Crona.B. (2012). On being all things to all people: boundary organizations and the contemporary research university. Social Studies of Science, 42(2):262-289.

[29]. Pennington, D. D., Simpson, G.L., McConnell, M.S., Fair, and J.M., Baker.R.J. (2013).

[30]. Transdisciplinary research, transformative learning, and transformative science.BioScience 63:564-573.

[31]. Phillipson, J., Lowe, P., Proctor, A. and Ruto, E. (2012).Stakeholder engagement and knowledge exchange in environmental research.Journal of Environmental Management, 95:56-65.

[32]. Pohl, C. \&Hadorn, G.H. (2007).Principles for Designing Transdisciplinary Research-proposed by the Swiss Academies of Arts and Sciences. Münche: oekomVerlag,.

[33]. Pohl, C. \&Hadorn.G.H. (2008).Methodenentwicklung in der transdisziplinärenForschung.In M. Bergmann, E. Schramm TransdisziplinäreForschung.Integrative Forschungsprozesseverstehen und bewerten. Frankfurt am Main: Campus.

[34]. Pohl, C. (2011). What is progress in transdisciplinary research? Futures 43(6):618-626 Pohl, C, Rist, S, Zimmermann, A, Fry, P, Gurung, GS, Schneider, F, IfejikaSperanza, C,

[35]. Kiteme, B, Boillat, S, Serrano, E, Hirsch Hadorn, G, Wiesmann, U. (2010). Researchers' roles in knowledge co-production: experience from sustainability research in Kenya, Switzerland, Bolivia and Nepal. Science and Public Policy, 37(4):267-281.

[36]. Raymond, C.M., Fazey, I., Reed, M., Stringer, L., Robinson, J. \&Evely.A. (2010). Integrating

[37]. local and scientific knowledge for environmental management. Journal of Environmental Management, 91:1766-1777.

[38]. Roux, D. J, \&Nel, J.L. (2013). Review: freshwater conservation planning in South Africa: milestones to date and catalysts for implementation. Water South Africa, 39(1):151-164.

[39]. Scholz, R.W. (2011).Environmental literacy in science and society. From knowledge to decisions. Cambridge: University Press

[40]. Smith, P.M. (2007). A transdisciplinary approach to research on work and health: what is it, whatcould it contribute, what are the challenges. Critical Public Health, 17(2): 159-169.

[41]. Stahl, C., Cimorelli, A.,Mazzarella, C., \& Jenkins, B. (2011). Toward sustainability: A case study demonstrating trans-disciplinary learning through the selection and use of indicators in a decision making process. Integrated Environmental Assessment and Management, 7(3): 483-498.

[42]. Toomey, A.H., Markusson, N., Adams, E. \& Brockett, B.(2015).Inter-and Trans-disciplinaryResearch: A critical Perspective. Retrieved from https://sustainabledevelopment.un.org/.../612558-Inter-\%20and\%20Tran... [Accessed: 13 ${ }^{\text {th }}$ August 2016].

[43]. Transdisciplinary Research on Energetics and Cancer (TREC).(2010). What is Transdisciplinary

[44]. Research?Retrieved from http://www.obesity-cancer.wustl.edu/en/About/what-is-transidsciplinary-Research.[Accessed: $15^{\text {th }}$ August 2016].

[45]. Tress, B; Gunther, R. and Fry, G. (2006).Defining concepts and the process of knowledge production in integrative research.Retrieved from http://library.wur.nl/frontis/landscape_research/02_tress.pdf.[Accessed: $2^{\text {nd }}$ July 2016].

[46]. Vilsmaier, U. (2014). Methods of transdisciplinary research. Retrieved from mhttps://complexitycontrol.org/methods-oftransdisciplinary-research/.[Accessed: $30^{\text {th }}$ August 2016].

[47]. Winder N. (2003). Successes and problems when conducting interdisciplinary or transdisciplinary (= integrative) research. In Tress B. et al. (eds.) Interdisciplinary and Transdisciplinary Landscape Studies: Potential and Limitations. Wageningen, Delta Series 2.

[48]. Zerfu, H., Endalkachew, T., Gizaw, D., \&Zewdu W. (2011).Baseline study report on Transact project micro-watershed research sites. Retrieved from https://www.oead.at/.../Manual_Research_Methods_in_Rural_Transform... [Accessed: 23 ${ }^{\text {rd }}$ August 2016]. 